\section{Public Health} Genomics
Public Health Genomics 2018;21:101-120

DOI: $10.1159 / 000497809$
Received: December 10, 2018 Accepted: February 6, 2019 Published online: April 4, 2019

\title{
Making the Most of Innovation in Personalised Medicine: An EU Strategy for a Faster Bench to Bedside and Beyond Process
}

\author{
Denis Horgana Jonathan A. Lal ${ }^{b, c}$ \\ a European Alliance for Personalised Medicine, Brussels, Belgium; ${ }^{b}$ Department of Molecular and Cellular \\ Engineering, Jacob Institute of Biotechnology and Bioengineering, Sam Higginbottom University of Agriculture, \\ Technology and Sciences, Allahabad, India; ' Institute for Public Health Genomics, Department of Genetics and \\ Cell Biology, GROW School of Oncology and Developmental Biology, Faculty of Health Medicine and Life Science, \\ Maastricht University, Maastricht, The Netherlands
}

\section{Keywords}

Personalised medicine $\cdot$ Innovation management .

Translational research $\cdot$ Technology transfer $\cdot$ Health technology assessment $\cdot$ Bench to bedside $\cdot$ Omics $\cdot$ Public health genomics Public health

\begin{abstract}
Personalised medicine promises to revolutionise healthcare, with its key goal of providing the right treatment to the right patient at the right time, and thus the potential of improving quality of life and helping to bring down healthcare costs. However, a major problem with broader implementation of personalised medicine is patient access to new drugs, devices and treatments. The fact that a new medicine or innovative product can sometimes take as long as 20 years to get from bench to bedside is not only clearly undesirable but is arguably unacceptable in the 21 st century. This paper looks in detail at the issues surrounding development, continued investment, risk factors, testing and approval from both the industry perspective as well as that of the assessor and the decision maker/payer. It becomes clear that there is a lack of
\end{abstract}

working in tandem that results in a double time frame (two times 10 years). This is simply because the key stakeholders, surprisingly, do not synergise their assessments of a new product. As well as causing delays in patient access, this can also affect investment confidence as industry waits too long for approval for its product to reach the market and its subsequent implementation into healthcare. Such a slow process undermines continued investment and contributes to a risk-averse environment, which in turn can have an impact on innovation. The solution appears to be uncomplicated, involving better coordination and collaboration between the different stakeholders working at various stages within the bench-to-bedside timeframe. We take the example of the network of the European Alliance for Personalised Medicine (EAPM) to demonstrate possible solutions using an innovative approach.

(c) 2019 S. Karger AG, Basel

D.H. and J.A.L. contributed equally in the preparation of the manuscript.

\section{KARGER}

(c) 2019 S. Karger AG, Basel

E-Mail karger@karger.com

www.karger.com/phg
Jonathan A. Lal

Rewa Road

Naini, Allahabad, Uttar Pradesh 211007 (India)

E-Mail jonathanalal@shuats.edu.in 


\section{Background}

The last 20 years have seen a substantial rise in genome-based ${ }^{1}$ information $^{2}$ and technologies ${ }^{3}$ (GBITs). These advances have been triggered by systems biomedicine as well as information and communication technologies [1].

This has led to the advent of personalised healthcare, where every person is considered to be unique with the potential of stratified, personalised and possibly individualised interventions tailor-made for every patient/citizen [2].

Patients and industry will benefit from successful realtime effective and efficient integration into healthcare of such personalised approaches, and this will be beneficial not only to the patient/citizen, but also to industry. The latter looks towards effective and timely technology transfer.

However, the uncertainty associated with this new scientific knowledge presents many risks for those involved in industry, with respect to the success of implementing their product/technology ${ }^{4}$ as well as for patients, health policy and decision-making.

In 2014 alone, personalised medicines were holding more than $20 \%$ of the US Food and Drug Administration's (FDA) approval share for novel drugs. This has increased since then [3]. Furthermore, the Obama administration approved USD 215 million of investment into the sector of personalised or precision medicine for 2016 [4].

In the European theatre, the Innovative Medicines Initiative II (IMI), the largest European public-private partnership (PPP), whose aim is to "speed up the development of better and safer medicines for patients," has committed huge amounts of resources towards personalised medicine [5].

The European funding scheme, Horizon 2020, and its successor the proposed Horizon Europe, have moreover

\footnotetext{
1 "Genome-based" includes all data deriving from the human genome (for example all omics: genomics, proteomics, metabolomics, etc.) as well as from the environment (for example life style, behaviour, social and economic environment, etc.).

${ }^{2}$ Genome-based information includes genome-environmental interactions and interoperability of all kinds of data deriving from various sources.

${ }^{3}$ Genome-based technologies are all related technologies derived from or based on the application to the human genome and their interoperability with other technologies such as laser, imaging etc. These technologies can be a technique, tool, methodology, process, device, diagnostic kit, medical application, drug, among others.

${ }^{4} \mathrm{~A}$ "technology" defined here can either be a technology in the traditional sense, a drug, diagnostic application, technique, method, process and tool.
}

earmarked several applications related to personalised medicine. Consequently amid other factors, personalised applications are moving from the lab to the market with sales rising in some sectors.

However, the introduction of these products into widespread healthcare usage is a long drawn-out process. Also, a review of current technologies, patents and literature available to actual usage in healthcare systems highlights a huge gap [6].

As a result, citizens, patients and industry are at a disadvantage. The patients fail to receive relevant treatment in real time, causing decreasing quality of life and life expectancy, while industry faces uncertainty regarding successful healthcare implementation and approval, which affects investment.

The primary aim of this paper is to provide a comprehensive overview of the functioning of the current pipeline of translational research. It also identifies the problems related to it and then proposes the way forward, while making use our own network of stakeholders and methods.

\section{The Pipeline of Translation Research}

The different phases of translation research can be divided into three chronological phases (Fig. 1) [6]:

- Phase 1: Lab to industrial application - The phase starts from the very first idea of a drug/technology/application in the lab and sees its realisation into a potential industrial application. This phase involves both basic as well as applied research and development. Phase 1 activities can take place in a lab at any research institution, university and/or industry base. Once a technology/drug target is identified, its feasibility as an industrial application is assessed, for example, with the help of spin-offs, small-to-medium enterprises, big pharma, etc.

- Phase 2: Industrial application to market - Phase 2 includes developing and preparing the product (drug/ technology) for introduction into the market and its subsequent push/pull. This phase sees the application/ idea developed into a tangible product and tested for feasibility. Marketing strategies, market approval and intellectual property rights issues are dealt with at this level. The drug/technology is consequently brought onto the market with ongoing sales and the start of return on investment.

- Phase 3: Market to healthcare system implementation - This phase starts after the product has reached 


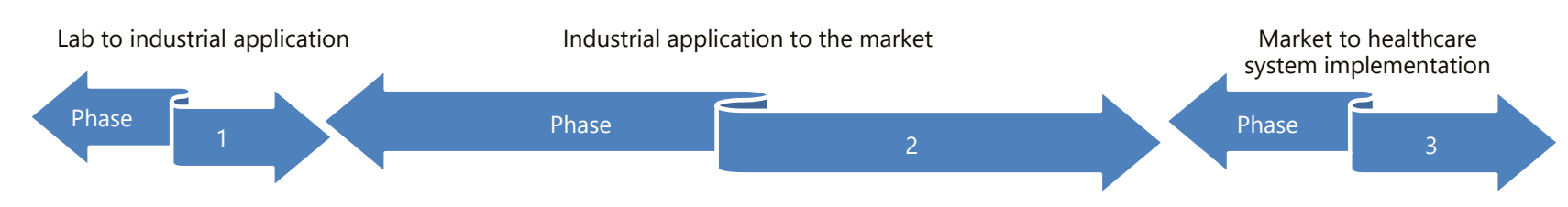

Fig. 1. Translational research: It can be divided into 3 phases as described in text above.

Color version available online

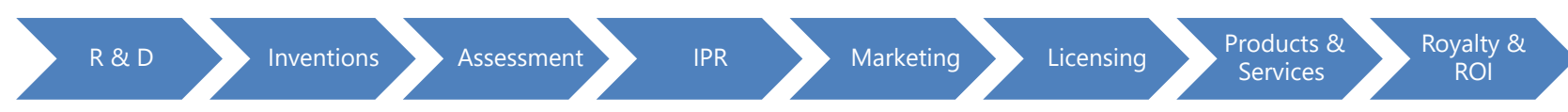

Fig. 2. Technology transfer (TT), an example: To translate ideas to the market, after initial research and development, an idea becomes an invention. This is then assessed for feasibility and investment, it is patented and protected. Thereafter, the technology is marketed and possibly licensed. Products and services are generated as a result, and this brings return on investment. This pipeline is not absolute and there is no one methodology of TT, although it revolves around these concepts. Figure itself adapted from [34]. the market and sales/revenues have already begun. The focus here is on health policy implementation, decision making, development of best practice guidelines and reimbursement with respect to the technology/ drug in progress. Phase 3 also encompasses the concept of "diffusion of innovations" which focuses on pushing the technology for widespread usage, also in healthcare and public health.

The first two phases are generally processed by technology transfer (hereinafter TT). TT (Fig. 2) can be defined as an activity of the migration of academic discoveries to useful application in the development of marketable products or processes [7].

This activity is mainly used by academics, industry, research institutes independent of each other or collaboratively (which we will in both circumstances call the "TT professionals" for simplicity) to valorise technologies from the lab to products on the market.

The TT activity also includes the drug development pipeline (Fig. 3). In stage I, the drug is tested for safety, administered amount and side effects in a small, healthy group of volunteers.

In stage II, the effectiveness, as well as safety, is analysed in a similar group. In stage III the drug is tested on a large group to establish the effectiveness, as well as to observe side effects and compare it with current treatments. Phase IV comes into play when the drug is approved and being used [8].

As stated earlier, TT also includes the drug development pipeline. An indicative sketch of this representation can be seen from Figure 4. This is not absolute and can vary between users.

TT professionals generally focus on the first 2 stages to develop and sell their product. The 3rd stage is mainly dominated by health policy professionals (regulators, health administrators, decision makers, policy makers, assessors, government, etc.).

To execute the $3 \mathrm{rd}$ stage, i.e. from market to healthcare system implementation, health policy professionals use a different toolset from TT, known as the public health assessment tools (PHAT) [6]. Decision (and/or policy) makers are presented with recommendations, developed through the PHAT process to assist them in making policy and decisions on the integration of that particular health technology into healthcare including reimbursement strategies, best practice guidelines, budget, etc. PHAT is the collective term for: 


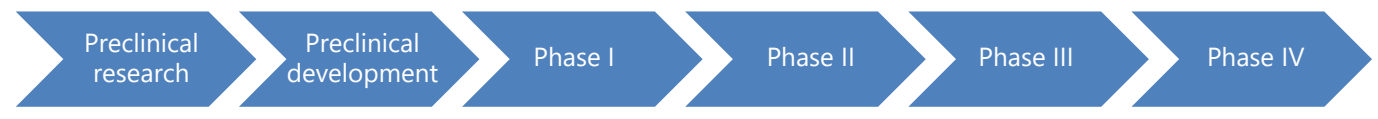

Fig. 3. Drug development: An indication of the drug development pipeline starting with pre-clinical research and development and ending with phase IV. Adapted from [8].

Color version available online

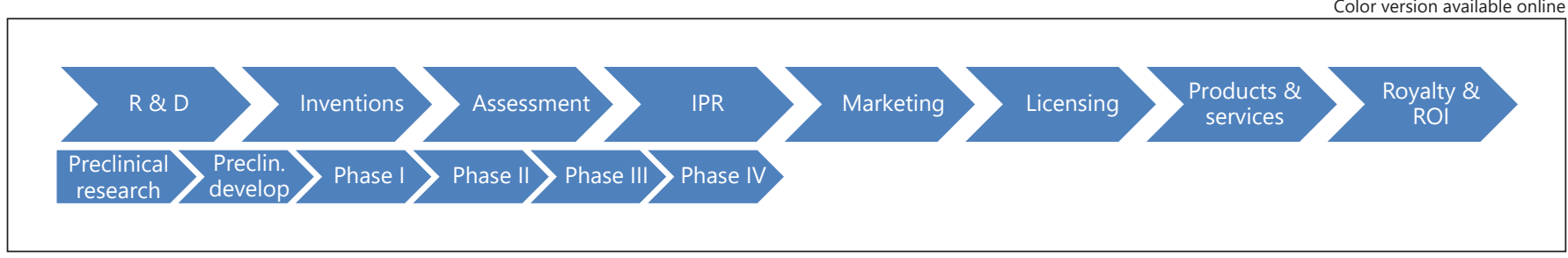

Fig. 4. Relation between technology transfer (TT) and drug development (DD): An indicative sketch of the inclusiveness of the DD pipeline within the larger TT pipeline. Extracted from [20].

- Health Needs Assessment (HNA) - This is a systematic method of reviewing health issues facing a population, leading to agreed priorities and resource allocation to improve health and reduce inequalities [9].

- Health Technology Assessment (HTA) - This is a multidisciplinary process that summarises information about the medical, economic, social and ethical issues related to the use of a health technology in a systematic, transparent, unbiased and robust manner [10]. See Figure 5 as a brief example of the HTA process ${ }^{5}$.

- Health Impact Assessment (HIA) - This is a combination of procedures, methods and tools by which a policy, programme or project may be judged as to its potential effects on the health of a population [11].

HNA, HTA (in particular) and HIA processes are mostly conducted by agencies that assess relevant or emerging technologies. They hereby develop recommen-

\footnotetext{
${ }^{5}$ It should be noted here that HTA also do their own needs assessment, but that is not part of the HNA. There may be overlaps in procedures between the different PHAT, but they are independent including methodologically from each other.

${ }^{6}$ Depending upon the region in the EU or elsewhere in the world, the PHAT agencies or professionals may vary. For example, the agency that undertakes the official HTA assessment for the decision maker in a country may not be titled as an HTA agency. Elsewhere, these three individual components may be merged or separated or mixed depending upon the region. This is more to indicate what tools are utilised or overlapped in PHAT. Nonetheless, these tools (HNA, HTA and HIA) are separate in their nature, irrespective if they are used by one agency or multiple agencies.
}

dations, which are taken into consideration by decision makers. These decisions influence best-practice guidelines and reimbursements among other things. It should however be stated that HNA, HTA and HIA have their separate and distinct methodologies.

Importantly, in several real-life cases, the relevant assessment agency only performs HTA. In which case, HNA and HIA take different forms. The associated HNA and HIA activities would in that case be conducted by different committees. These committees may conduct HNA and HIA without being labelled as such. HNA and HIA, regardless, have the potential to directly or indirectly influence the prospects of health technologies being integrated into healthcare.

The policies determined by these so-called budgetary committees could work against the development of a particular relevant technology. It is therefore important to identify the actors in charge of HIA and HNA at specific levels, while keeping in mind that some roles may overlap.

Similarly, HTA agencies may or may not be designated as such. For example, the United States (US) does not have a designated HTA agency but rather a particular department in charge of the task $[12,13]$, whereas in Germany [14] and Spain [15] there are designated HTA agencies $^{6}$.

Labelling of agencies should categorise the different actors into HNA, HTA and HIA for a clear structure of objectives by these stakeholders. 


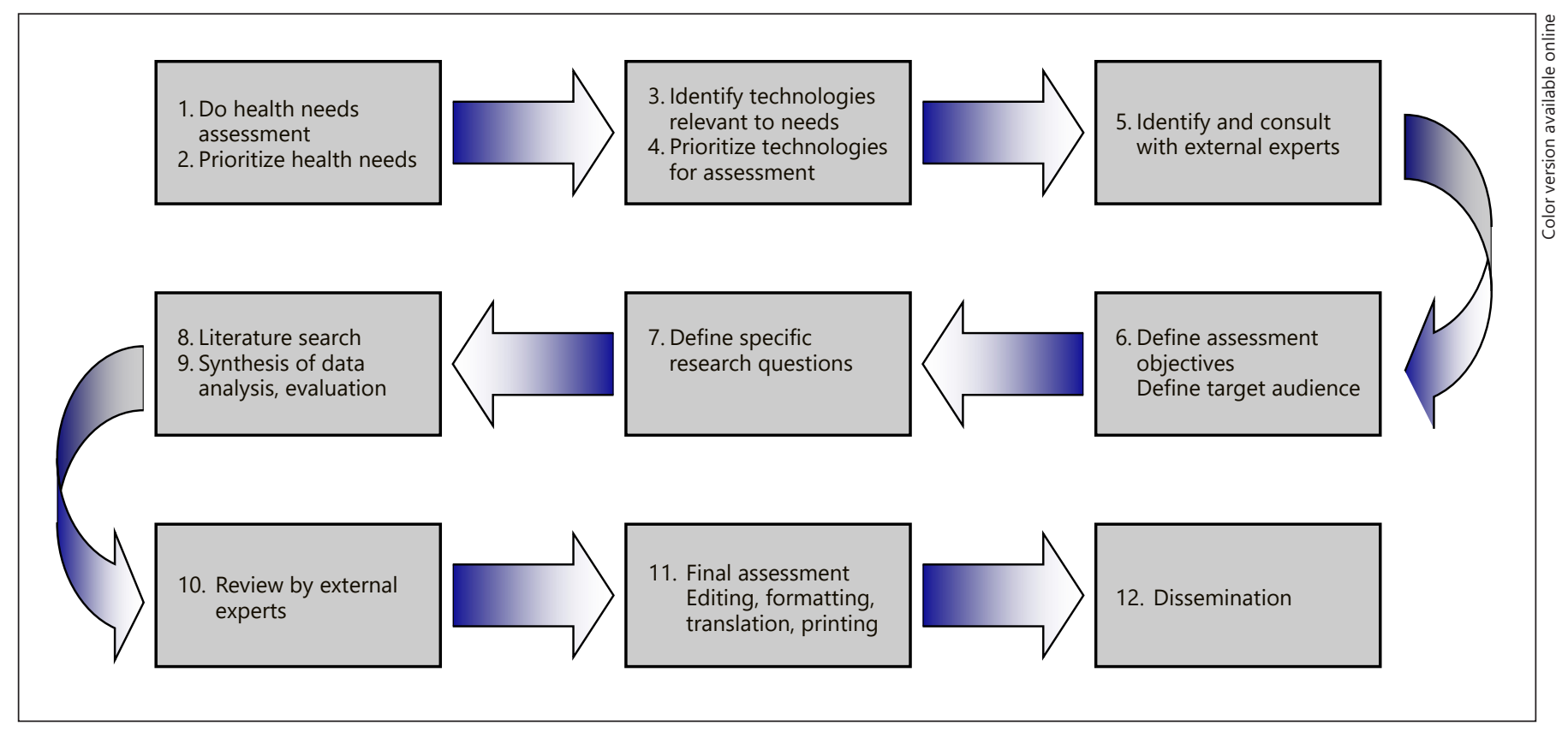

Fig. 5. An example flow chart of health technology assessment (HTA): The health needs assessment in the first phase should not be confused with the independent health needs assessment (HNA) of public health assessment tools (PHAT) as the health needs assessment of HTA is different from the actual HNA of PHAT. The last phase of HTA is in the form of recommendations for decision makers. Figure taken from [35].

Public health issues are an important aspect that ought to be taken into account when discussing the pipeline. According to the World Health Organisation, public health can be defined as "all organised measures (whether public or private) to prevent disease, promote health, and prolong life among the population as a whole" [16].

The public health application of emerging technologies is generally overlooked through the development and implementation of a particular personalised application. The fact that the technology gains approval based on PHAT recommendations does not, however, guarantee that it will address public health issue.

This could contribute to a failure to capitalise due to lack of usage in public health applications. Therefore, public health aspects are important factors towards the success of genome-based technologies or health innovations.

The Institute of Medicine (IoM) in the US, defined three core areas or functions of public health, namely assessment, policy development and assurance [17]. Public health was summarised as the Public Health Wheel adopted for Public Health Genomics (PHG), as can be seen from Figure 6 and Table 1 [18].

Making the Most of Innovation in Personalised Medicine
This framework has been widely used by the Public Health Genomics European Network (PHGEN I and II) [www.phgen.eu] to develop best-practice guidelines for quality assurance, provision and use of GBITs by different stakeholders at European Union (EU) level.

These guidelines were endorsed by the European Medicines Agency (EMA) and all EU Member States alongside other stakeholders [19]. The PHG Wheel demonstrates the integration of GBITs into public health by addressing the 10 essential tasks in the translation of the technology in question into public health. These 10 essential tasks are important factors when it comes to successfully integrating the technology into the public health domain.

The complete translational research pipeline (Fig. 1), taking into account TT (Fig. 2-4), PHAT (Fig. 5) and public health (Fig. 6), is summarised in Figure 7.

It is important to note that phases 1-2 combined can last from 5 to 10 years [20]. The third phase can take additional 5-10 years [21, 22]. Emphasis should be put on the separations between phases 1-2 and phase 3 .

Although shown in chronological order, methodologies are not synchronised. It should be noted that, for example, in Germany and the Netherlands, access to tech-

Public Health Genomics 2018;21:101-120 
Fig. 6. The public health wheel: The 10 essential tasks of public health which need to be addressed for widespread use of genome-based technologies. Taken from [18]. Table 1 describes these tasks in further detail.

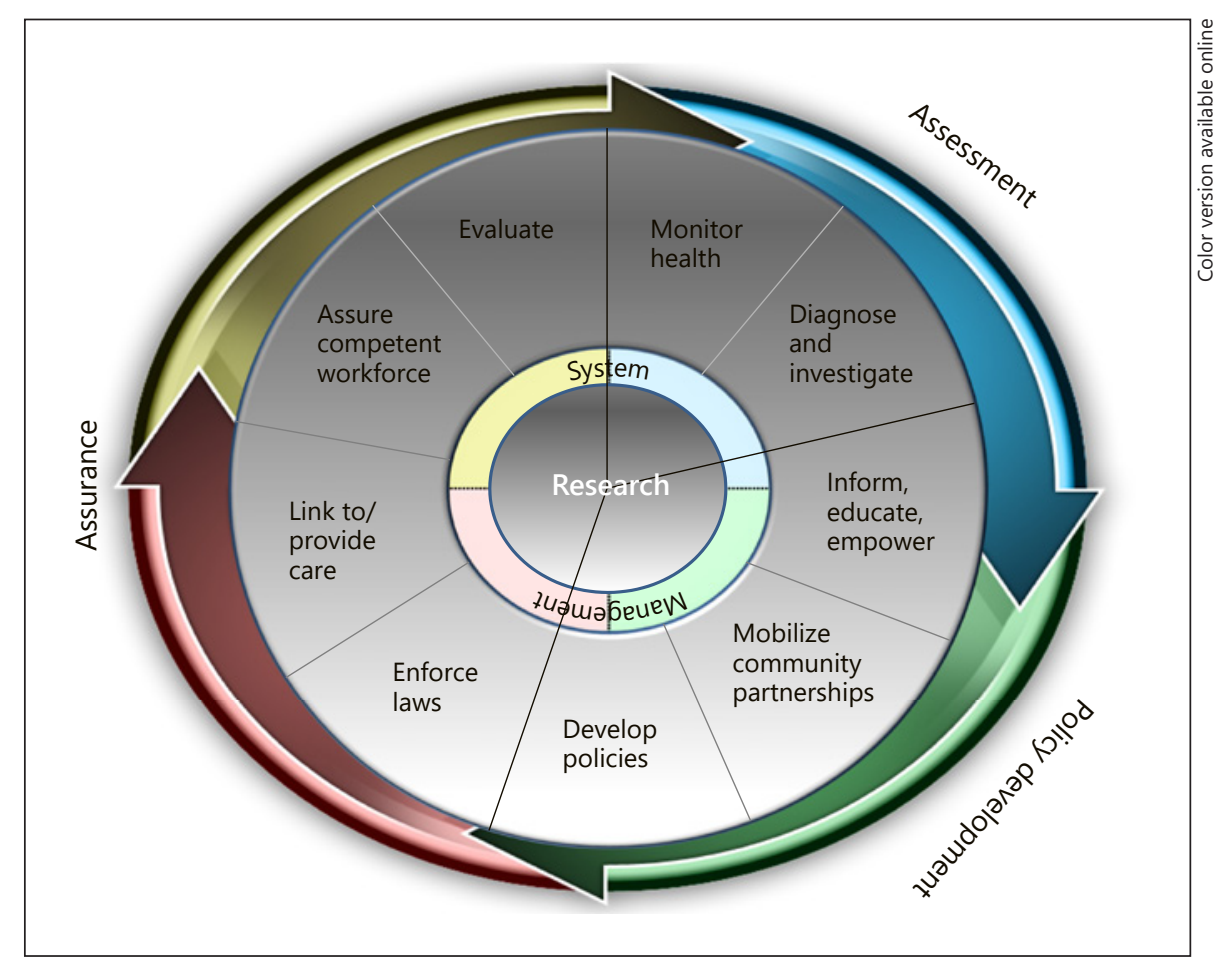

nologies emerging from the development and regulatory approval are rather fast within TT.

However, the 5-10 years in the TT pipeline includes the timeline from the first idea to the penetration into the market. This process can either be fast (5 years) or slow (10 years) depending upon the type of technology.

On the other hand, the PHAT process does not start and end from "bench to bedside." It rather starts after market penetration to diffusion and wide usage in healthcare systems.

Some experts argue that the process of HTA starts even earlier with horizon scanning [23] and constructive HTA [24]. This view, however, is limited to the screening of emerging technologies or ideas in the public domain and not what the industry is working on in-house (for example, trade secrets). As a result, by the time the innovation reaches the public domain, the gain in time will be minimal.

Additional hurdles, such as lack of awareness amongst physicians and concerns regarding costs and healthcare payer approval, can add up to 10 years to the overall process. There is, in fact, a lack of guidelines and standardised information at the European level.

Many experts have argued that limited resources dedicated to the implementation and spread of translational research frameworks hinders the way forward. As such, there is a need for Europe-wide advocacy for personalised benefits.

Additionally, it has been advocated that actions oriented towards raising awareness amongst healthcare professionals and industry stakeholders should be taken.

\section{Macro-, Meso- and Micro-Levels in the Translational Research Pipeline}

Another aspect to be addressed is defining the levels of the conceptual framework (phases 1-3, Fig. 7), and for these defined levels, their respective involvement, problems and solutions which we define below:

- Macro-level: This level deals with the complete translational research pipeline encompassing all three phases (1-3). Solutions and advice are given at a meta-level point of view (for example, the PHGEN best practice guidelines) [19]. This can bring the individual components at the lower level (e.g., TT and PHAT) in different aspects to address the problem of delay in healthcare integration and the fragmentation of the translational research pipeline. Macro-level has the complete picture, as well as what comes next and links them together. 
Table 1. Details of the 10 essential tasks of public health divided over the three domains of assessment, policy development and assurance

\begin{tabular}{ll}
\hline Assessment (2) & Core function \\
Monitor Health & The regular systematic collection, assembly, analysis and dissemination of personal health \\
Diagnose and investigate & information including genome-based information and technologies (GBITs) \\
& Related essential services \\
& - Basic research: quantifying the impact of GBITs and their interaction with environmental \\
& factors including knowledge from epigenomics, microbiome etc. \\
& - Monitoring health: monitoring health status, including genome-based factors, to identify \\
health problems within the healthcare system & - Diagnosing and investigating: investigating the distribution of genome-based and modifi- \\
& able risk factors to determine their contribution to identified health problems and to improve \\
health outcomes
\end{tabular}

Policy development (3)
Inform, educate, empower
Mobilise community partnerships
Develop policies

\section{Core function}

The formulation of standards and guidelines, in collaboration with stakeholders, which promote the appropriate use of GBITs and the effectiveness, accessibility and quality of their tests and services

Related essential services

- Policy and communications research: identifying and analysing the economic, social, ethical and political implications of advances in GBITs, including the information and communications needs of stakeholders

- Informing, educating, and empowering: facilitating communications and education about the integration of GBITs into health promotion and disease prevention programs

- Mobilising partnerships: fostering collaboration between public and private agencies and constituent groups to promote effective and efficient communication and policy making about GBITs

- Developing policies: establishing standards and guidelines for when and how genetic information should be applied to promote health and prevent disease

Assurance (4)
Enforce laws
Link to/provide care
Assure competent workforce
Evaluate

\section{Core function}

Assuring constituents that GBITs are used appropriately and that tests and services meet agreed-upon goals for effectiveness, accessibility and quality

\section{Related essential services}

- Health services research: identifying and analysing the factors that influence the impact of GBITs and the delivery, utilisation and quality of health information and services

- Enforcing laws: promoting the enforcement of policies and standards enacted to ensure the appropriate use of GBITs and the effectiveness, accessibility and quality of genome-based (health) information and services

- Linking to/providing care: ensuring the availability and accessibility of GBITs and services and associated interventions to improve health and prevent disease

- Assuring a competent workforce: ensuring that present and future healthcare professionals have training and skills in the appropriate use of GBITs to promote health and prevent disease

- Evaluating: evaluating the impact of GBITs and the effectiveness, accessibility and quality of this information and related services

System management $(1)$ Building and maintaining the capacity of the public health infrastructure to integrate GBITs into public health policy, research and practice

Each of these domains has a certain amount of tasks given in brackets. See Figure 6. Adapted from [20].

- Meso-level: This level covers the individual phases separately or, for example, TT and HTA as individual components independent from each other. It addresses fragmentation, problems, solutions and frameworks. For example, what issues the current TT pipe- line as a whole faces and with respect to the stakeholders in that particular pipeline.

- Micro-level: This level covers specific problems within certain sections or steps in the pipeline. This includes steps described within TT or steps described within 


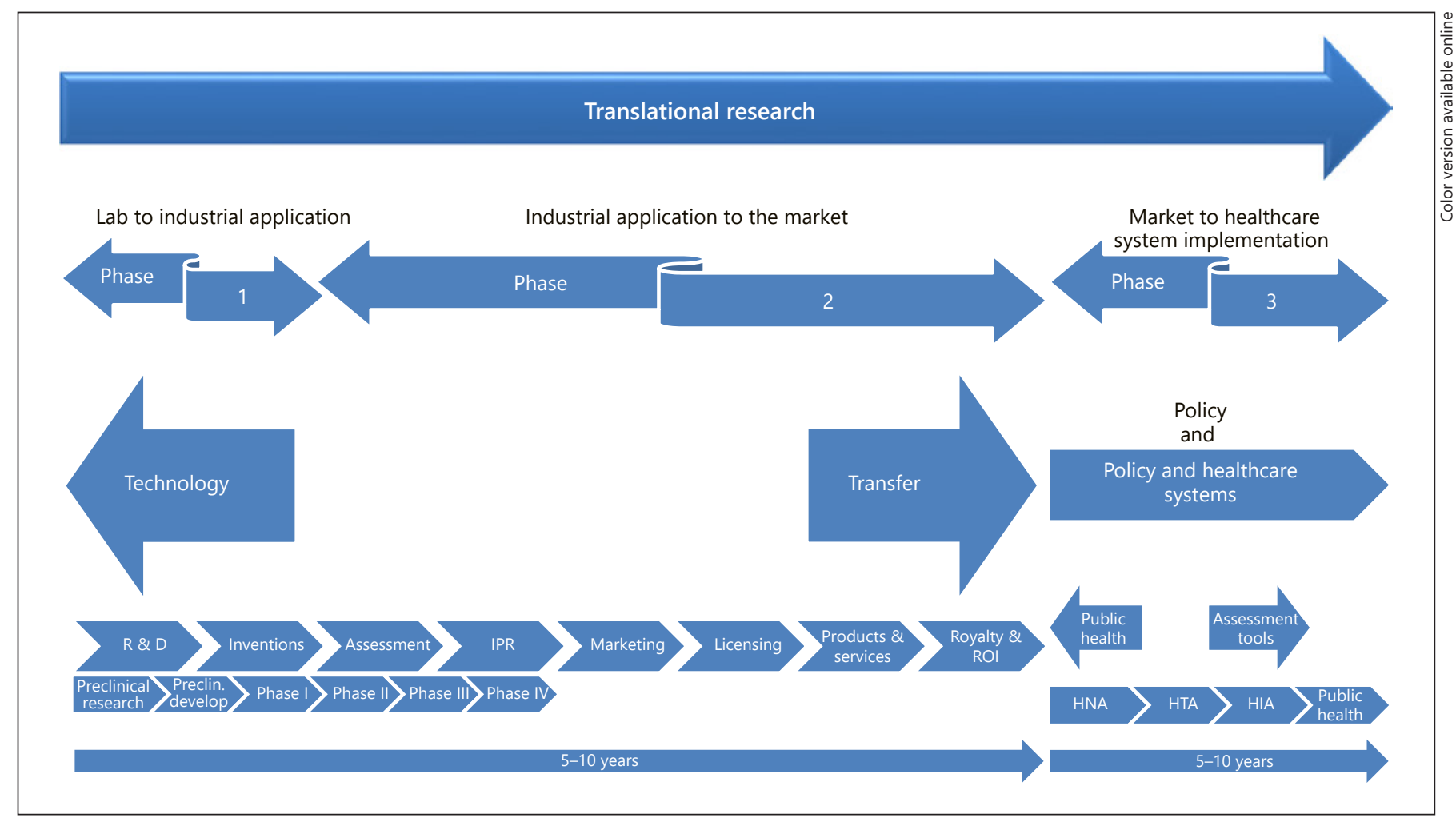

Fig. 7. The pipeline is translational research from bench to bedside and beyond into healthcare: The 2 nd row indicates the phases mentioned earlier. The $3 \mathrm{rd}$ row (left to middle) indicates the coverage of technology transfer (TT). The 3 rd row right indicates the coverage of healthcare as a whole. The 4 th row (starting from the left) indicates the TT pipeline from basic idea to commercialisation and return on investment (this is indicative but not absolute). The 4th row, on the right, indicates the coverage of the public health assessment tools (PHAT). The 5th row (left) indicates an

HTA. It deals with the real-world practical problems and solutions. For instance, a certain step in TT may not be suitable or may conflict with the translational process. Taking, for example, the process of licensing within the TT pipeline (Fig. 7), including the stakeholders involved solely in that process and addressing roadblocks in that licensing process. This also covers the end-user utilisation of the solution in that particular step.

The macro-level provides an overview of the complete pipeline and the problems and link ups between the phases. This can help to focus on problems at the meso-level and address the relationships. An overview of the mesolevel can give an outline of the problems in individual pipelines. A thorough understanding of the meso-level can help give a push towards the identification of micro- example of the drug development pipeline which falls within TT above. The 5th row (right) indicates the components of the PHAT used by decision makers. The 5 th row extreme right shows where public health issues fall. The last row indicates the timelines through these steps. TT and PHAT are independent and not synergised. By the time the technology reaches the market, it will have taken 5-10 years. Next, the assessments occur, and these take more than 5-10 years. Adapted from [31].

problems. The micro-level can give an overview of individual issues at a particular step of a methodology which can then be addressed. This can be seen from a top-down approach and/or bottom-up approach.

The translational research pipeline for personalised medicine alongside its three levels (micro, meso, macro) can be considered universal at an EU level. Although the translational pipeline processes are similar across the EU, some exceptions subsist (like the HNA, HIA and HTA procedures mentioned previously). Case-specific details are, however, restricted to the regional/national level.

The regional requirements may for example, differ from region to region regarding a particular technology. The principles of the translational research pipeline nonetheless remain transcendental both at EU and regional level. 
Focus should therefore be primarily allocated at EU level while maintaining capacity to deal with case-specific issues at regional level.

An EU-wide consensus on the bottlenecks in the translational research pipeline would open doors at the regional levels. Furthermore, EU-wide policy development and implementation regarding issues in the translational research pipeline would facilitate inter-regional cooperation on the bottlenecks.

This could lead to a transfer of best practices between the EU and the different regions and vice versa. Figure 8 provides an overview of this translational research pipeline.

\section{Shortening the Timelines for Patient Access}

As stated earlier, TT alone takes 5-10 years, including clinical trials, before market introduction. Ten additional years are required for the completion of PHAT and its individual HNA, HIA and HTA components, leading to a total of 20 years ${ }^{7}$ before the technology reaches wide usage in healthcare.

As a result, the technology might be outdated by the time it becomes commonly used in healthcare. In spite of recent initiatives to encourage early dialogue, there is no structured and efficient stakeholder involvement throughout the decision making process that decreases the timeline and investment uncertainty [25].

An example of delayed implementation is the diagnostic kit Mammaprint [26], which is used as a predictor for breast cancer. It was initially rejected by the HTA agencies in Malaysia [27] and Australia [28] due to its undetermined clinical utility and was not recommended by the International Network of Agencies for Health Technology Assessment (INAHTA) [29].

Had the HTA been in a systematic and earlier dialogue with industry, it could have been perceived differently and time would have been saved. As of now, Mammaprint is only completely reimbursed in the Netherlands compared with other EU countries.

EMA has taken a step in the right direction with the pilot adaptive/staggering licensing concept [30]. This may be considered as a meso-level solution. The aim of this strategy is to reduce the timeline related to the approval of drugs.

However it only covers a certain section of the pipeline (Fig. 7) and is not systematic in its integration of other components, such as HTA, etc. The focus of this adaptive licensing is to reduce the time to market within the TT pipeline by getting HTA agencies involved throughout the development.

Unfortunately, it neglects the implementation into healthcare which is generally the next step. In summary, it fails to reduce the overall time for implementation into healthcare as it does not address the complete pipeline from bench to implementation. It focuses on early authorisation of the drug, ignoring the health implementation itself ${ }^{8}$.

However, according to Figure 8, EMA's approach covers the TT pipeline possibly reducing the steps until "marketing" and involves stakeholders in the process, as well as HTA to a certain extent. A more systematic approach is, however, required to address these issues at meso- $/ \mathrm{mi}$ cro-level.

EMA's focus on the TT pipeline through its pilot adaptive licensing programme and the parallel assessments of HTA should reduce the timeline. However, this is not sufficient.

In addition to the above, the public health perspective needs to be taken into account in this multi-stakeholder participation for development (TT), assessments (PHAT), public health requirements (PHG wheel) and ultimate implementation into healthcare-wide usage.

The model searched for or developed should therefore be overarching, fulfil all individual components (like HNA, HTA, HIA, public health aspects, TT and the value of the information gathered) and involve key stakeholders working in parallel on different components.

\section{Uncertainty of the Implementation Process}

Several models have been developed, such as the ACCE (analytical validity, clinical validity, clinical utility and ELSI [ethical, legal and social implications]), EGAPP (evaluation of genomic applications in practice and prevention), T1-T4 (translational research 1 to translational research 4), Public Health Enterprise, etc. but all of them lack certain features and have been criticised (Table 2) [31]. They are not able to address uncertainty early on.

\footnotetext{
${ }^{7}$ Although from the perspectives of pharmaceuticals, the EU has a reimbursement process restricted by law in Europe to 180 days/transparency directive (although longer in other countries), the time period given here is indicative of not only reimbursement, but including health policy decision making and healthcare implementation based on these assessments. Also, the real-life methodology of HTA itself can range from 5 to 10 years.

${ }^{8}$ There is recognition in the EMA that other stakeholders are key for this process but, however, do not have a systematic integration of these key stakeholders.
} 


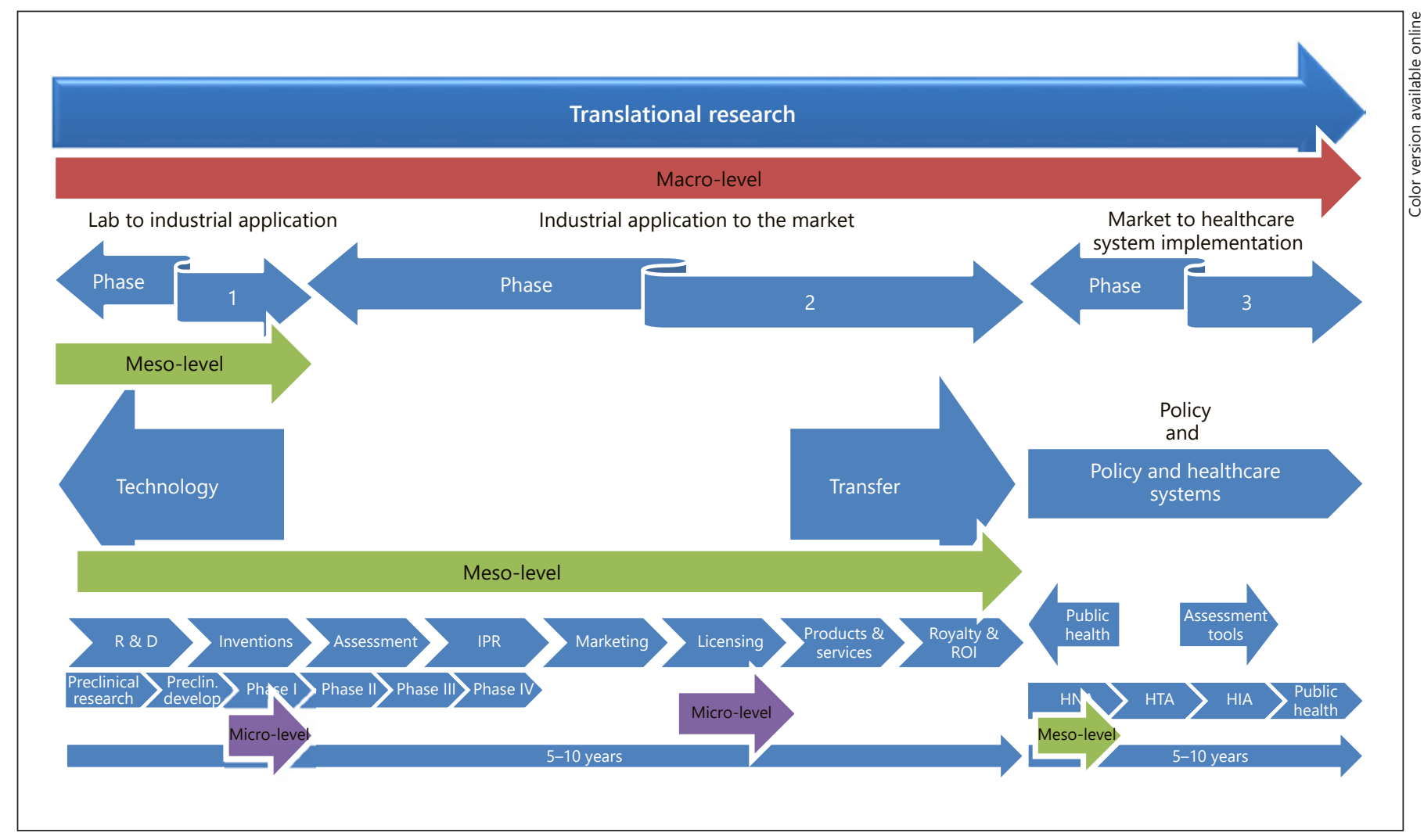

Fig. 8. The complete translational research pipeline demonstrating the macro-, meso- and micro-levels: As can be seen in red, macrolevel addresses an overarching view at a meta-level on the issues, problems and existing frameworks at the level of the complete translational pipeline. Meso-level represented in green covers either a single phase (in this case phase 1), or a complete methodology (in this case technology transfer [TT] or health needs assess- ment [HNA]). Micro-level, represented in purple, covers a specific section of a method/pipeline (in this case, phase I of the drug development pipeline or licensing of the TT pipeline). From Figure 5, addressing a single step of health technology assessment (HTA) would be the micro-level, whereas the whole HTA pipeline would be meso-level.

Table 2. Limitations of ACCE, EGAPP, T1-T4 and the Public Health Enterprise

\begin{tabular}{lll}
\hline No. & Framework & Limitations \\
\hline 1 & ACCE & All of these do not cover the complete pipeline (Figure 7) \\
\hline 2 & EGAPP & $\begin{array}{l}\text { Constrained only to evaluation of genetic tests, based on deterministic and linear } \\
\text { understanding of genetics and genetic diseases and limited only to clinical settings, limited } \\
\text { geographically }\end{array}$ \\
\hline 3 & T1-T4 & $\begin{array}{l}\text { Builds on ACCE but is again limited geographically, and is from the perspective of human } \\
\text { genetics and genetic epidemiology and generally used for genetic tests }\end{array}$ \\
\hline 4 & Public Health Enterprise & $\begin{array}{l}\text { Does not have any defined methodology on how to fulfil these phases in a timely fashion, just } \\
\text { mentions the obvious }\end{array}$ \\
\hline
\end{tabular}

For further details see [31]. 
We need to identify or develop such a (macro-level) framework/model. It ought to fulfil the above criteria (Table 2) and tackle the bottlenecks at the meso- and micro-level that are blocking effective, efficient and timely integration of genome-based technologies in real time for personalised applications in healthcare.

This bottleneck is disadvantageous to both industry and patients. Not a single model can address the problem of delayed translation (from lab through the market into healthcare implementation) and uncertainty of success of such personalised applications. Each model is limited in one way or another. There is no full coverage of the pipeline (Fig. 7), no systematic involvement of key stakeholders. There is no unified front and no complete coverage.

If industry can be informed early on whether a technology/drug will be accepted or rejected in its current state, it can either adapt to ensure success, or terminate development to save further loss on investment.

A third route is to go ahead into the traditional smaller market. For the patient, delayed approval of drugs and health technologies can have a significant negative impact and potentially increase the burden of disease.

The current scenario calls for a new framework which can:

- Incorporate all necessary components mentioned in the models above

- Include the HNA, HTA and HIA more clearly in time and cooperation

- Take into account the TT activity for technology development

- Reduce the timeframe to integration in healthcare

- Be a better predictor of successful implementation

- Address the effective integration of socially accountable personalised healthcare strategies

- Reduce fragmentation and non-synergy between TT and PHAT

- Promote logical, scientific and timely decision making

- Involve key stakeholders early and increase cooperation across sectors

- Ensure that differences in regional healthcare systems do not affect the model and can be easily compensated for

- Address all steps of the pipeline with defined methodologies and steps

We will now present our method to achieve the current demand as mentioned above using the example of the network of European Alliance for Personalised Medicine (EAPM).

Making the Most of Innovation in

Personalised Medicine

\section{Methods}

Stakeholders should understand the levels presented in Figure 8 (micro, meso and macro) and allocate themselves accordingly in the complete pipeline. This can help identify problems around those issues. Levels can therefore be described as follows:

- Locate placement in the pipeline from macro-, meso- and micro-levels

- Define problems at that location

- Define current solutions at that location

- Develop new solutions and address new problems

To elaborate further, the steps indicated in the translational research pipeline are fragmented and no formal linkups are made at the macro-level. There are also issues of uniformity at the mesolevel and individual practical problems at the micro-level.

There is no efficient synchronised crosstalk in time between the relevant stakeholders to resolve these issues. They are working in their separate silos. It is important to resolve this by:

- Making stakeholders aware of their individual silos, through placement in the translational research pipeline on the 3 levels

- Involving these stakeholders earlier based on their labelling/ placement for crosstalk and partnerships

- Developing solutions and formal linkups between different sections at the meso- and macro-level

- Ensuring that related stakeholders discuss the micro-problems and develop solutions

We will use the members of EAPM, including working groups (WGs) within the Alliance as well as organisational members in a pilot study to demonstrate our objectives. However, it should be noted that this labelling will not encompass all necessary stakeholders, but will rather be the first step of many.

In order to achieve the above points, the following steps would be required, a few ( 1 and 5 for indicative purposes, as $2-4$ follow through within point 1 ) of which we will demonstrate as the starting point:

1 Label the current WGs and EAPM members onto Figure 8 (macro-level). The positioning of these WGs will define the location of meso-level issues per WG.

(a) When categorised, these WGs' relation to the process can be identified and moving engagement forward can be looked at.

2 Extrapolate from these WGs individual stakeholders and plot them on Figure 8. This would localise the micro-level issues per stakeholder and their involvement in the pipeline.

(a) From the above, different types of activities of engagement can be explored at micro-level, developing a framework of actions.

3 Ascertain the roles at the micro-, meso- and macro-level of these WGs and stakeholders in Figure 8 and initiate PPPs through these phases.

4 Include the missing stakeholders onto this existing sketch for interactions.

5 Based on Figures 9-11, rearrange these stakeholders and WGs on the macro-level to reduce the timeline from 20 to 10 years. This would mean early/parallel involvement of relevant stakeholders.

(a) Trainings and workshops can be used for this process.

A questionnaire developed by the research team and based on the barriers to personalised medicine published in the literature [32]. 


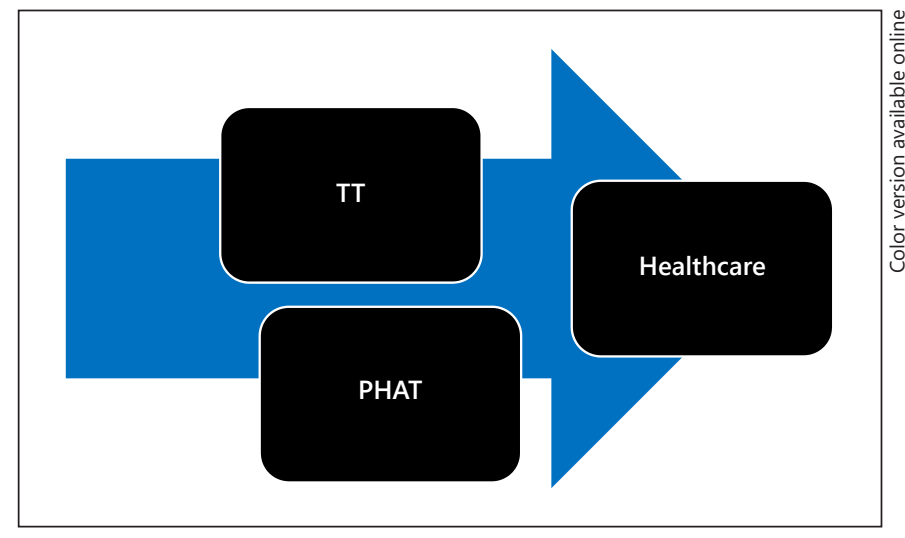

Fig. 9. An example at a macro-level on how to reduce the timeline: This can be done by taking the 10 years of technology transfer (TT) and 10 years of public health assessment tools (PHAT) and reducing them to an average of 10 years through parallel collaboration.

\section{Macro}

1 What type of an organisation do you identify yourself as? You may choose more than one.
(a) Industry
(b) Government
(c) NGO
(d) Patient group
(e) Insurance
(f) Health policy
(g) Public-private partnership
(h) Other, please specify

2 With respect to a health innovation in personalised medicine, which parts in the translational pipeline are you involved in? You may choose more than one.
(a) Valorisation to the market
(b) Bench to beside
(c) Reimbursement
(d) Approval
(e) Licensing
(f) Health policy
(g) $\mathrm{R} \& \mathrm{D}$
(h) Clinical trials
(i) Public health application
(j) Societal integration
(k) General healthcare
(l) Patient access
(m) Health technology assessment
(n) Health needs assessment
(o) Health impact assessment
(p) Others, please specify

Meso

1 Please choose one of the sub-pipelines of translational research in which you actively work. If you work in more than 1, please repeat the question with that sub-pipeline as well.
(a) Technology transfer
(b) Drug discovery and development
(c) Health technology assessment

(d) Health needs assessment

(e) Health impact assessment

(f) Public health access

(g) Health policy

(h) Best practice guideline development

(i) Approval and licensing

(j) Others, please specify

2 Do you face structural and/or framework problems in that particular sub-pipeline as a whole?
(a) Yes
(b) No
(c) Not sure, or maybe

3 Are these problems due to factors within that sub-pipeline or due to interactions with actors outside that pipeline?
(a) Within
(b) Outside
(c) Both
(d) Not sure or not applicable

4 Could you specify the type of structural problem?

(a) Stakeholder involvement synergy problem

(b) Standardisation across regions

(c) Interoperable infrastructure

(d) Policy making bureaucracy and/or gaps

(e) Lack of funding

(f) Lack of data and research

(g) Healthcare system itself

(h) Patient access

(i) Reimbursement

(j) Others, please specify

For the last step (5th step), we will use the principles of the Learning-Adapting-Levelling model $[6,20]$ as the guiding framework.

According to this framework, TT including drug development can, on the one hand, take from 5 to 10 years depending on the technology/drug being developed. And on the other hand, PHAT takes another 10 years.

Parallel timelines for TT and PHAT can ensure that by the time the technology is rolled out of the TT pipeline, it has been adapted and conforms to healthcare requirements (see Fig. 9). This can hypothetically reduce the overall duration from 20 years to 10 , on average. A more detailed overview can be seen from Figure 9.

This parallel strategy can also help industry to make an early strategic decision based on the assessments rather than a too-late one. A parallel strategy can ensure early involvement with all key stakeholders. Regarding this macro-decision making model, the way forward would be to initiate a parallel initiation between TT and PHAT after the labelling of the first four steps as mentioned above, unlike their separate decoupled process, to reduce the overall time and bring the remaining relevant components of the various models mentioned above in Figure 8.

This simultaneous initiation of TT and PHAT as given in Figure 10 can be elaborated further in the example of Figure 11. According to Figure 11, after research and development and after initial analysis of their developing technology, the industry approaches the HNA professionals for their view and feedback/assessment on the developing technology.

Based on HNA professionals' feedback and assessment, industry can go back to the drawing board and adapt. Similarly in chronological order they do the same with HTA and HIA professionals. 


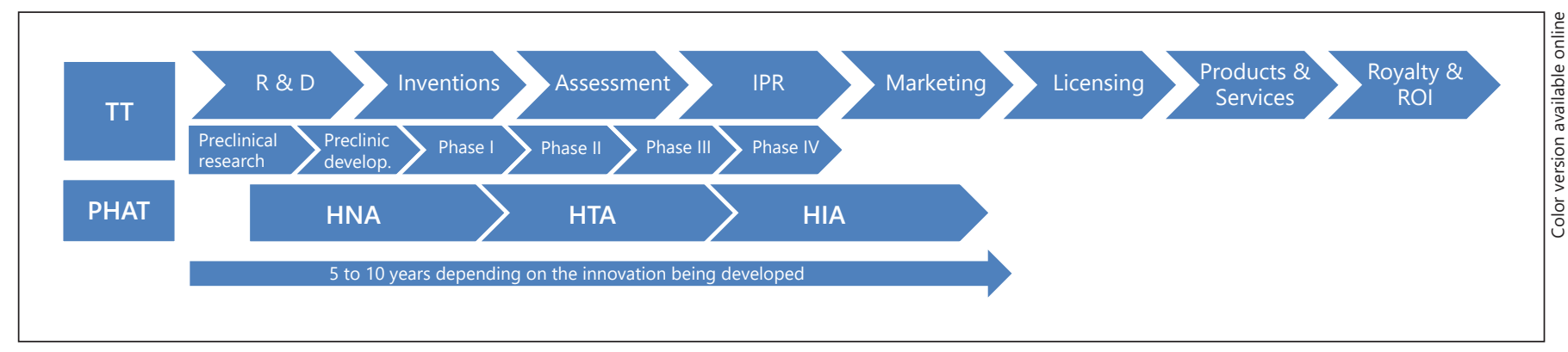

Fig. 10. A detailed breakdown of figure 9: First two rows show the technology transfer (TT) pipeline with the 2nd row showing the clinical trials pipeline. The third row shows the public health assessment tools (PHAT) pipeline, including the simultaneous nature when these assessments should take place to reduce the timeline. HNA, health needs assessment; HTA, health technology assessment; HIA, health impact assessment. Taken from [20].

Only within the HTA, other stakeholders such as patient groups, insurance, public health professionals, doctors, health policy makers, etc. are involved in the feedback process and continue henceforth.

Over several iterations, collaborations can be converted into broadly defined PPPs, which we can call the innovation network (Fig. 11).

This Figure 11 is what we envision as the actual final interactions once things are in place. It should be noted that the full scale of our vision can take 5 years at least; therefore, similarly we have left out other steps mentioned in this methodology section.

The reason to limit matters to just this aspect is to show the reader the way forward so other actors can initiate similar actions. Hopefully, in the next 5-or-so years, we will be able to publish our results. As it stands, this is more of a proof of concept towards the proof of principle in 5 years. Also this is EAPM-specific, but can be adapted to other actors.

\section{Results and Discussion}

The EAPM brings together European healthcare experts and patient advocates involved with major chronic diseases. The aim is to improve patient care by accelerating the development, delivery and uptake of personalised medicine and diagnostics, through consensus.

The mix of EAPM members provides extensive scientific, clinical, caring and training expertise in personalised medicine and diagnostics, across patient groups, academia, health professionals and industry.

Relevant departments of the European Commission have observer status, as does the EMA. EAPM has a number of WGs, which cover the following areas (www. euapm.eu):

- Big data

- Education and training of healthcare professionals

- Early access and better decision making

Making the Most of Innovation in

Personalised Medicine
- Research roadmap for personalised medicine

Based on the roles of members in EAPM, they have been categorised in the three phases. Figure 11 divides the current work packages of EAPM and some members indicatively of Table 3 based on Figure 7 and the questionnaire.

This is the first time that, to our knowledge, such a labelling has been done and will be the first step in several as indicated in the methodology. Based on this labelling, prospective interactions can be planned with different stakeholders to resolve bottlenecks.

It should be noted however that other stakeholders mentioned in Figure 11 such a HTA, and policy makers among others, are already defined in their location of interactions, and therefore are not labelled here separately for the sake of simplicity.

Additionally, since this is EAPM specific, other actors in the current pipeline are not mentioned for the clarity of the members' roles as a first step. However, the next steps would include these other actors to develop interactions accordingly.

Figure 8 shows the parallel labelling of EAPM members based on their role to reduce the timeline (using the learning-adapting-levelling model as mentioned in the Methods section).

Based on Figure 9, certain stakeholders (doctors, policy makers, patient groups, etc.) enjoy a predefined location and are labelled. They will, however, be included in the further interactions.

In order to reduce the timeline to healthcare implementation, i.e. early patient access, and to reduce the industry's uncertainty for this implementation, the logical action would be to develop PPPs between key stakeholders involved throughout the pipeline, once they realise

Public Health Genomics 2018;21:101-120 
Table 3. An indicative assessment of various EAPM stakeholders in the 3 phases of translational research

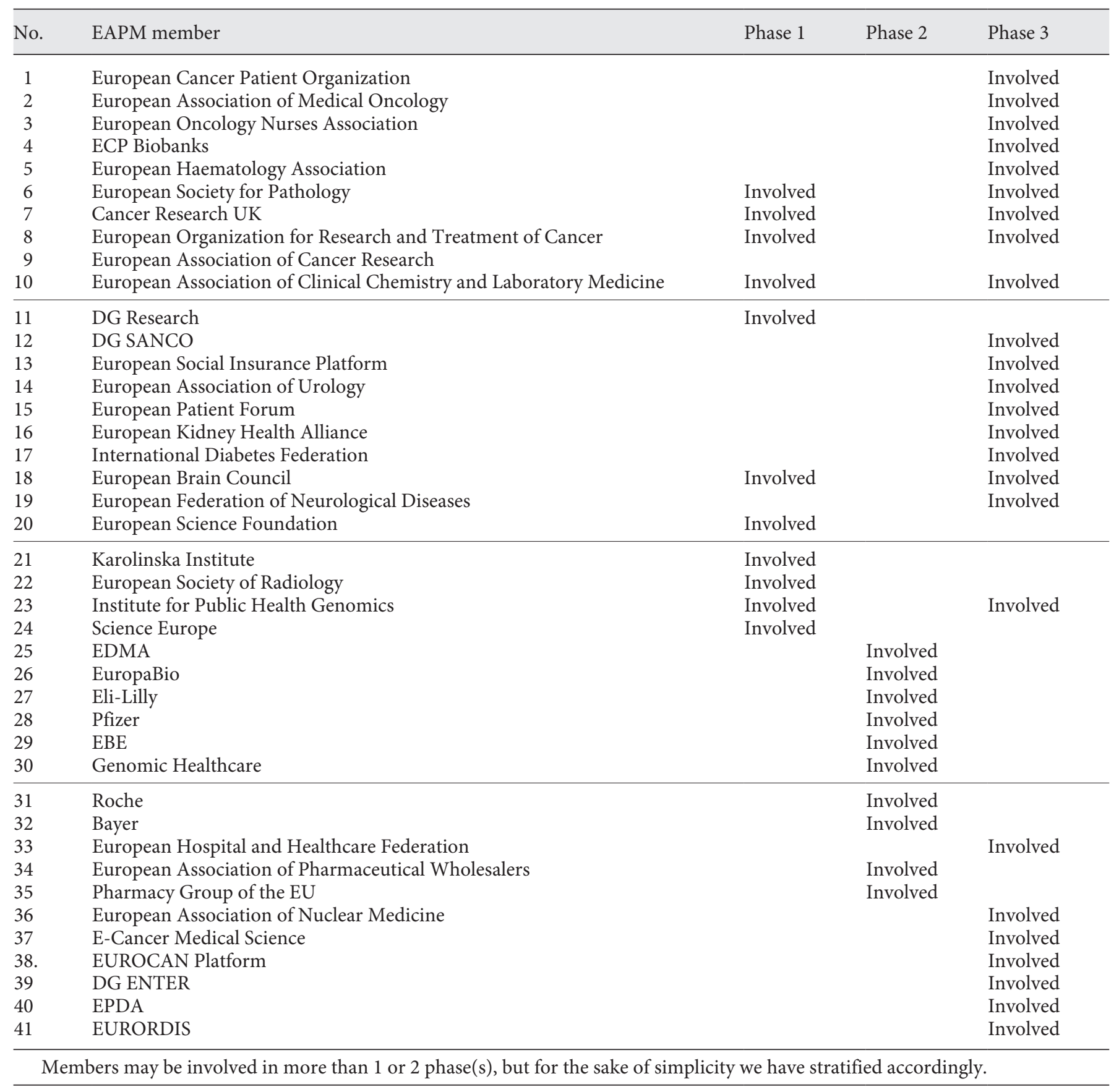

their roles. This would be followed by bringing them to the table to execute parallel assessments (Fig. 12). This should involve the following:

- Early stakeholder engagement throughout the pipeline, including policy makers and/or decision makers, doctors, patient groups, industry, academics, insur- ance, hospitals, public health authorities, HNA, HTA and HIA assessors among others

- This can be achieved via meetings, workshops and conferences with all key stakeholders. These meetings can be content-based (macro, meso) or based on the stakeholders (micro) at a particular step of the pipeline. 


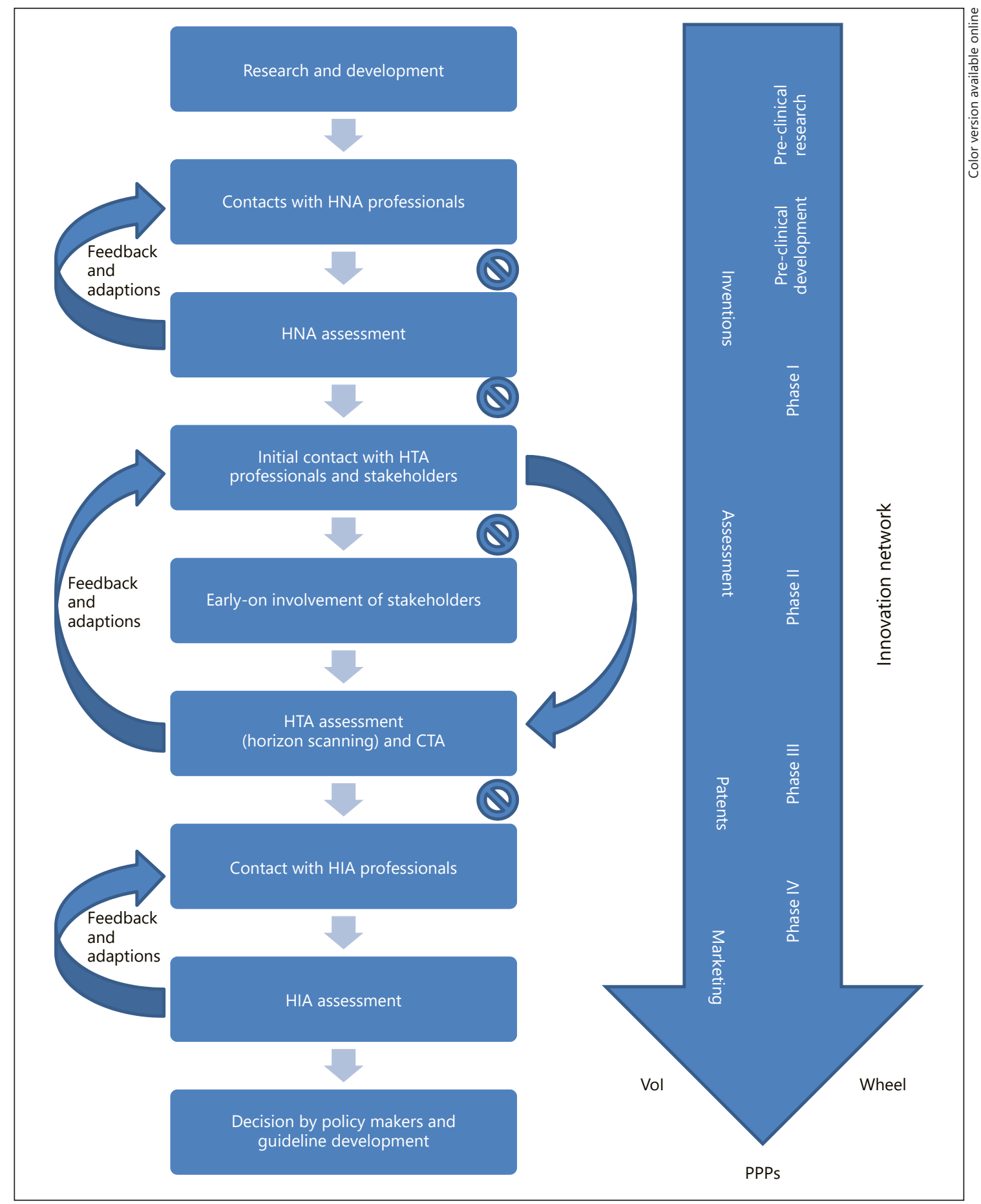

Fig. 11. An example of how parallel initiation between public health assessment tools and technology transfer (TT) should take place at a macro-level: The right column indicates the TT pipeline, VoI is value of information. The wheel in the right column is the public health wheel (Fig. 5). These public-private partnerships (PPPs) develop a network of interactions called the innovation network. Taken from HTA, health technology assessment and HIA, health impact assessment [20]. 


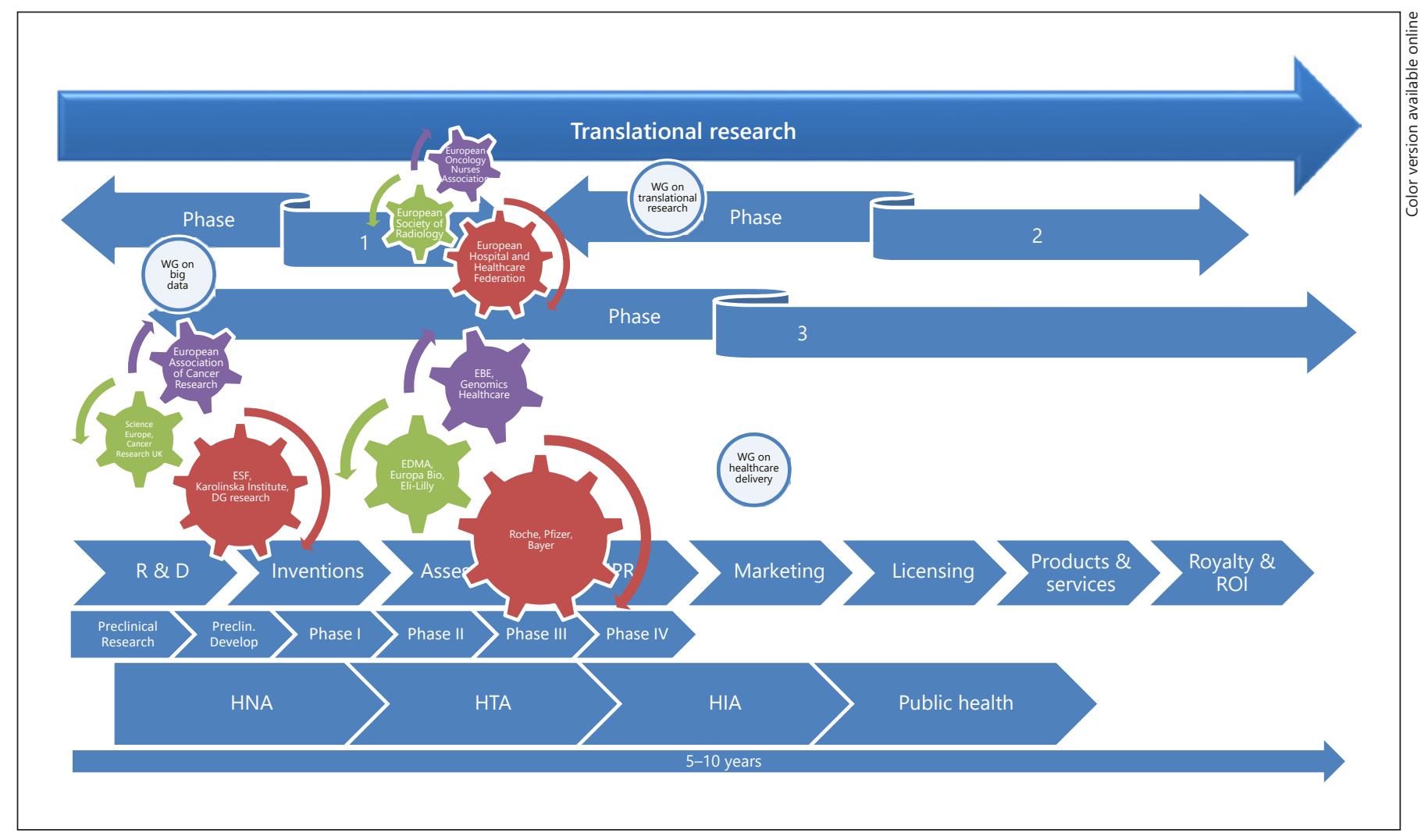

Fig. 12. Indicative labelling of certain working groups (WGs) and members within EAPM: This is done onto the macro-pipeline in order to define meso-level issues which, when addressed in turn, will address micro-level issues when further subdivided. This labelling is subject to further reshuffling based on the mandates of each WGs and member associations but is a starting point. Due to lack of space, we did not show all members but placed them in Table 3. HNA, health needs assessment; HTA, health technology assessment; HIA, health impact assessment.
- Develop new emerging WGs among different stakeholders over the complete pipeline, based on their roles (Fig. 13) and change the timeline to parallel WGs (Fig. 12). This placement of stakeholders and WGs will automatically bring into the picture the meso- and micro-level issues.

- Pilot studies with emerging genome-based technologies for testing and reducing the timeline

- Develop joint proposals and apply for projects

- Develop broadly defined PPPs, which involve bi-lateral communications, consultation, collaborations, development of frameworks, etc.

Through this involvement of all key stakeholders and major components of assessment and pipeline development, a better predictor of success can be established. for:

The result of these action points would pave the way
- Developing an inventory of the most common barriers to patient access after research and development and regulatory approval are complete

- Evaluating existing proposals and/or practices to reduce or streamline hurdles

- Make clear what needs to be applied at the regional/ member state level and what needs to be applied at the EU level

- Assist in developing recommendation and best practices

Through various EU Presidencies, EAPM has advocated towards this direction. Furthermore, we have presented and shown our vision at various meetings throughout the years.

This has contributed and led to the "Council Conclusions on Innovation and Patient Access to Personalised Medicine" of 1 December 2014 and the signing of a Joint Declaration to collaborate on a ground-breaking 1-mil- 
lion genomes project in April 2018, with which we have actively engaged.

This brings a political and relevant policy dimension to this and it brings added value to the argument.

The Council conclusions on innovation and patient access take an encompassing view at the translational research pipeline for innovative medicinal products. It furthermore stresses the need to support innovation and thereby foster patient benefits [33].

The paper advocates for early stakeholder involvement and dialogue and for a more efficient use of existing regulatory mechanisms in order to shorten the time in the pipeline [34].

The EU additionally acknowledges the potential effects of innovations on the health systems and budgets of European member states. The EU thus puts a "life-cycle approach" forward for innovative medical innovations.

This approach pleads for comprehensive stakeholder involvement and thorough assessment of the innovations. It should be noted that there are overlaps between Europe's approach and the pipeline labelling of EAPM stakeholders conducted previously.

As can be seen, through our steps mentioned in the methodology section, we automatically address these articles and are self-speaking and self-fulfilling through our methodology. We plan to move forward in this direction through our steps with EAPM members and associated stakeholders.

In addition, it should be stated that the European Union has recently taken big steps towards the inclusion of personalised medicine in the agenda. The Luxembourg presidency of the European council in fact acknowledged the need for more coordinated action at the EU level.

In line with the findings of this paper, European policymakers stress the need for an approach involving multiple stakeholders. The presidency also stressed the central role of communication and collaboration between the different actors involved in the translational research pipeline.

It was also suggested that a European Translational Research Platform should be established in order for the different parties to share expertise and thus foster the translation of scientific discoveries into innovative treatment and diagnostic options.

In light of such major advances, we can conclude that the EU has started to realise the importance of translational research and personalised medicine for patient benefits.

Importantly, these interactions promote active involvement of patient groups. The experience and perspective of patients are valuable items that can inform, for

Making the Most of Innovation in

Personalised Medicine example, an HTA. The views of patients can help to provide first-hand insights about life with a condition, experience with current technologies, and in the most soughtafter aspects of a new treatment.

These perspectives can inform trial designs that include important patient outcomes and that do not put burdens on the patients financially. Trials could thus be improved in terms of compliance and maximisation of data collection.

In the appraisal phase, patient evidence can inform discussions about the added value of a new technology and generally inform the value judgements of researchers and decision-making committees. This patient input becomes even more important when there is sparse scientific evidence, as may be the case in personalised medicine.

\section{Conclusions}

This paper describes the current situation surrounding the translational research pipeline alongside its problems and the lack of framework. It further goes on to sketch the complete translational research pipeline and label, as examples, members of EAPM across this pipeline.

Furthermore, it provides suggestions for the way forward to reduce the timeline by bringing this labelling in parallel using the Learning-Adapting-Levelling model and re-labelling EAPM members accordingly. In addition, it proposes steps and actions to synergise the pipeline stakeholders according to the Council's conclusions.

Having stated the above, this approach nonetheless remains hypothetical and is yet to be proven. Nonetheless, with logic and structure defined in the background section, it appears to be a valuable approach to the issue.

However, this is EAPM specific and may vary for other actors or stakeholders in their own map of reality, but the principle of this pipeline holds.

Prospectively, there are more milestones as defined in the methodology section that need to be achieved over a period of 5-10 years from the start of the health innovation and including the relevant stakeholders. Not all stakeholders of EAPM are, in fact, required for a particular health innovation or genome-based technology.

In addition, the public health professionals as predefined in the current framework (Fig. 7 and 8), including insurance, patient groups, clinicians and doctors among others, have to be added according to their roles, here (Fig. 12). 


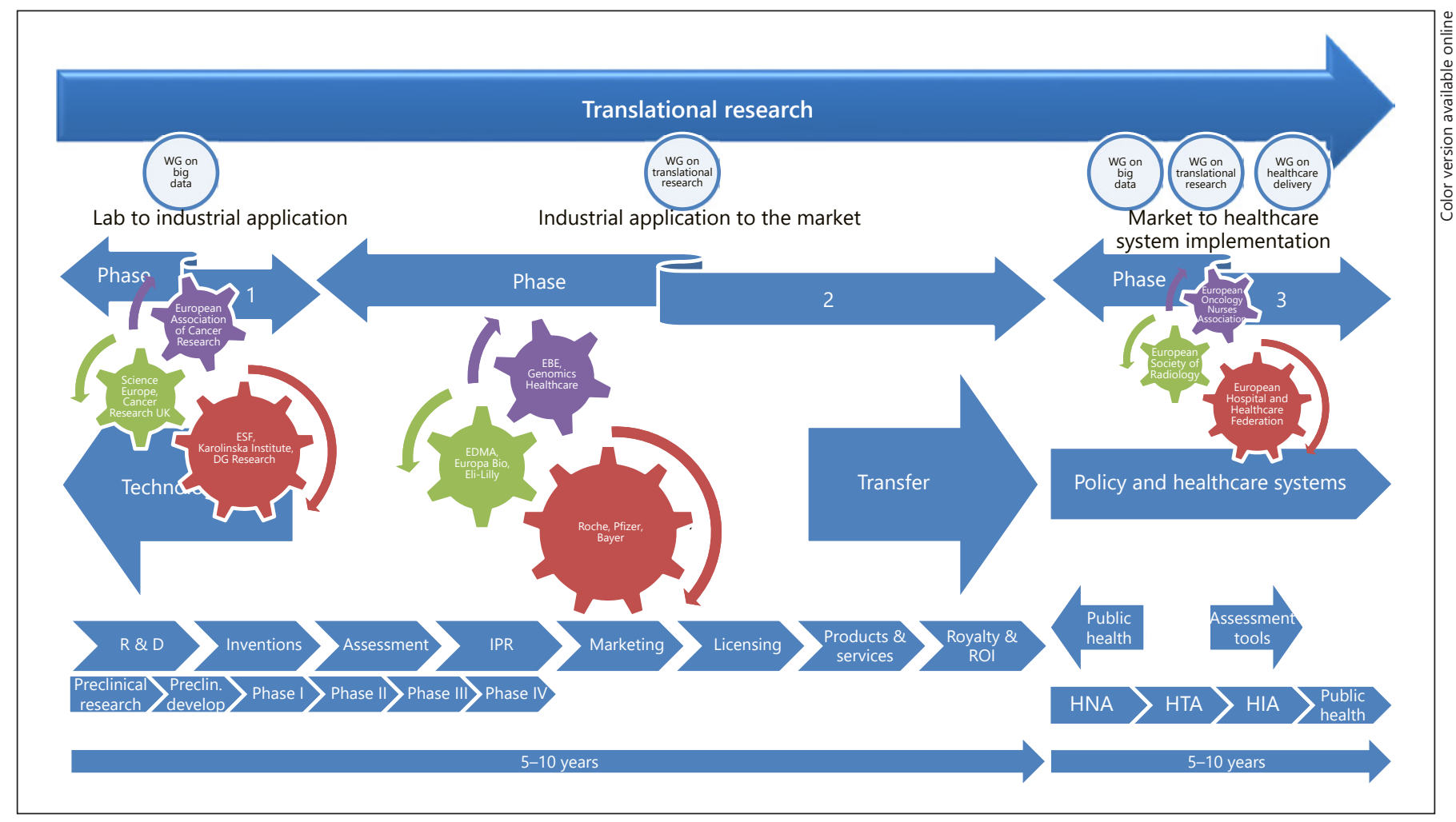

Fig. 13. Prospective labelling of EAPM members tentatively on the parallel pipeline: This is more indicative than absolute; also health policy professionals have to be included once the roles of each member are defined and resolved. WG, working group; HNA, health needs assessment; HTA, health technology assessment; HIA, health impact assessment.

As of now, and as argued in this paper, one must understand that although in principle the translational research pipeline exists as this paper indicates (Fig. 7), the reality of the situation is that communication between the different stakeholders is fragmented and based on trial and error.

Thanks to the clearer picture of the pipeline provided by this paper, stakeholders can and will understand their relevance and position within it and can initiate proper communication with the relevant actors, or other stakeholders, for the health innovation development and implementation. Furthermore, different initiatives by governments and industry will facilitate this communication.

Although this may streamline the process (which is the first intention), this will unfortunately not decrease the timeline, which is a major problem to patient access and return on revenues.

The next logical action following the positioning in the pipeline (Fig. 7) is streamlined-based steps and actions, given the methods and discussion sections, respectively.
Public health professionals are active as well according to their position mentioned, and a relabelling (Fig. 12) of stakeholders using Figures $10-11$ and 13 could be done to reduce the timeframe for patient access and investment returns.

This will in the first iterations be case-specific, i.e. to the technology in question and the region of implementation. Over time, this can become daily practice and streamlined.

In conclusion, it can be stated that this paper contributes to clarifying the reality of the situation and its problems and proposes the way forward with clear steps aiming to reduce the timeframe for early patient access, and reducing the risk of investment by early on involvement of all relevant stakeholders.

In parallel, the current trial-and-error and experience base will continue in valorisation of health innovations and, hopefully, this fragmented pipeline will become clearer through our paper and our currently successful advocating in the EU. 
Eventually the long-term goal is to bring assessments of health technologies in parallel, specifically for personalised applications.

As this paper goes into print, we have already started collaborating with various agencies, patient groups and industries, including government and the EU, to push this agenda forward.

In the meantime, we hope other readers of this paper can and will utilise this idea to push forward relevant health innovations in personalised medicine at their regions, realising the importance and fragmentation of the pipeline.

This collective paper will be our approach towards a better EU strategy in personalised medicine implementation into society, which will result in making the most of such health innovations in healthcare in a timely, logical as well as effective and efficient manner possibly reducing the time to patient access as well as risk on investment.

\section{Acknowledgements}

We would like to thank Ansgar Hebborn (Head Market Access Policy, F. Hoffmann-La Roche AG), Prof. Servaas A. Morré from the Faculty of Health, Medicine and Life Sciences at Maastricht University, the Netherlands), and Karen Facey (Honorary Senior Research Fellow, Health Economics and Health Technology Assessment, University of Glasgow, UK) for their insights on the paper.

\section{Disclosure Statement}

The authors declare that they have no competing interests.

\section{Author Contributions}

J.A.L. and D.H. conceived, built and drafted the idea.

\section{References}

1 Lal JA, Sudbrak R, Lehrach H, Brand A. Functional Dynamics: From Biological Complexity to Translation and Impact in Healthcare Systems. J Comput Sci Syst Biol. 2013;6(2): $88-92$.

2 Cesuroglu T, van Ommen B, Malats N, Sudbrak R, Lehrach H, Brand A. Public health perspective: from personalized medicine to personal health. Per Med. 2012 Mar;9(2): $115-9$.

3 Analysis PM. More Than 20 Percent of FDA's 2014 Novel New Drug Approvals are Personalized Medicines. Sys-Con Media. 2015. Available from: http://www.sys-con.com/ node/3289325

4 FACT SHEET: President Obama's Precision Medicine Initiative. Office of the Press Secretary, The White House. 2015.

5 The Innovative Medicines Initiative. http:// www.imi.europa.eu/

6 Lal JA, Schulte In den Bäumen T, Morré SA, Brand A. Public health and valorization of genome-based technologies: a new model. J Transl Med. 2011;9:207.

7 Mullins B, Crowe J. Technology Transfer: A Roadmap. College and University Auditor. 1999.

8 Phases of Drug Development. http://www. pkdcure.org/research/drug-development/ timeline

9 Cavanagh S, Chadwick K. Health Needs Assessment - A Practical Guide. London: Health Development Agency; 2005.

10 Health Technology Assessment (HTA). http://www.eunethta.eu/about-us/ faq\#t287n73
11 Health Impact Assessment. Main Concepts and Suggested Approach. The Gothenburg Consensus Paper. WHO Regional Office for Europe. Brussels: WHO European Centre for Health Policy; 1999.

12 Eisenberg JM, Zarin D. Health technology assessment in the United States. Past, present, and future. Int J Technol Assess Health Care. 2002;18(2):192-8.

13 Sullivan SD, Watkins J, Sweet B, Ramsey SD. Health Technology Assessment in HealthCare Decision in the United States. Value Health. 2009;12(2):S39-43.

14 The German Agency for Health Technology Assessment. German Institute of Medical Documentation and Information. http:// www.dimdi.de/static/en/hta/dahta/ [accessed 2015 February 3].

15 Osteba, Osasun Teknologien Ebaluazioaren Zerbitzua / Basque Office for HTA. http:// www.osanet.euskadi.eus/osteba

16 Public Health. World Health Organization. https://www.who.int/phi/implementation/ trade/en/ [accessed 2019 Feb]

17 The Future of Public Health. Washington: Institute of Medicine; 1988.

18 Beskow LM, Khoury MJ, Baker TG, Thrasher JF. The integration of Genomics into public health research, policy and practice in the United States. Community Genet. 2001 Jul; $4(1): 2-11$.
19 Brand A, Lal JA; Public Health Genomics European Network. European Best Practice Guidelines for Quality Assurance, Provision and Use of Genome-based Information and Technologies: the 2012 Declaration of Rome. Drug Metabol Drug Interact. 2012;27(3):177-82.

20 Lal JA, Vaidya A, Gutiérrez-Ibarluzea I, Dauben HP, Brand A. The Learning-Adapting-Leveling Model: from theory to hypothesis of steps for implementation of basic genome-based evidences in personalized medicine. Per Med. 2013 Sep;10(7):683-701.

21 Trochim W, Kane C, Graham MJ, Pincus HA. Evaluating translational research: a process marker model. Clin Transl Sci. 2011 Jun;4(3): 153-62.

22 Berwick DM. Disseminating innovations in health care. JAMA. 2003 Apr;289(15):196975.

23 Robert G, Stevens A, Gabbay J. 'Early warning systems' for identifying new healthcare technologies. Health Technol Assess. 1999;3(13): $1-108$.

24 Douma KF, Karsenberg K, Hummel MJ, Bueno-de-Mesquita JM, van Harten WH. Methodology of constructive technology assessment in health care. Int J Technol Assess Health Care. 2007;23(2):162-8.

25 Call for tender no EAHC/2013/Health/09 concerning pilots on early dialogue between health technology assessors and healthcare product developers during the development phase of medicinal products and medical devices. European Commission. 2013. Available from: http://ec.europa.eu/eahc/health/tenders_H09_2013.html 
26 MammaPrint. Agendia. http://www.agendia. com/healthcare-professionals/breast-cancer/ mammaprint/ [accessed 2018 Dec 3].

27 MammaPrint. Health Technology Assessment Section Medical Development. Division of Health Malaysia; 2008.

28 Health Policy Advisory Committee on Technology: Technology Brief Gene expression profiling of breast cancer. 2012 May.

29 MammaPrint. International Network of Agencies for Health Technology Assessment. 2009. http://inahta.episerverhotell.net/Publications/Briefs-Checklist-Impact/2009/4096/ [accessed 2015 February 3].
30 European Medicines Agency launches adaptive licensing pilot project. European Medicines Agency. 2014. http://www.ema.europa. eu/ema/index.jsp?curl=pages/news_and events/news/2014/03/news_detail_002046. jsp\&mid=WC0b01ac058004d $5 \mathrm{c} 1 \quad$ [accessed 2015 Feb].

31 Lal JA, Morré SA, Brand A. The overarching framework of translation and integration into healthcare: a case for the LAL model. Per Med. 2014 Jan;11(1):41-62.
32 Horgan D, Jansen M, Leyens L, Lal JA, Sudbrak R, Hackenitz E, et al. An index of barriers for the implementation of personalised medicine and pharmacogenomics in Europe. Public Health Genomics. 2014;17(5-6):287-98.

33 Council conclusions on innovation for the benefit of patients. Brussels: Employment Sp, Health and Consumer affairs Council meeting, 2014.

34 What is the technology transfer process? http://cmsserv.ncat.edu/doclib/DORED, $\% 20$ Outreach\%20and\%20Technology\%20Transfer $\% 20 \% 28$ How $\% 20$ To $\% 20$ Section $\% 29 \% 20$ Web\%20site,-5.pdf 